\title{
Spectroscopy-based study on the interaction between gold nanoparticle and poly (vinylpyrrolidone) molecules in a non-hydrocolloid
}

Manoranjan Behera ${ }^{1,2^{*}}$ and Shanker Ram ${ }^{2}$

\begin{abstract}
The study of the interaction between poly(vinylpyrrolidone) (PVP) and gold (Au) nanoparticles (NPs) in a colloid is of special interest for possible applications in the field of catalysis, biosensing, and biomedicine. A strong optical absorption arising from Au NPs at $532 \mathrm{~nm}$ in Au-PVP colloids is ascribed to surface plasmon resonance. The X-ray photoelectron spectroscopic results confirm reduction of the $\mathrm{Au}^{3+}$ ion to $\mathrm{Au}^{0}$. A noticeable decrease in the binding energies of the Au4f doublet peak of the Au NP with PVP as compared to the bulk Au atom implies interfacial interaction between the Au NP and PVP molecules. A marked enhancement in vibrational band intensities of C-H $\left(2,961,2,936\right.$, and 2,872 $\left.\mathrm{cm}^{-1}\right)$ stretching, $\mathrm{C}-\mathrm{N}\left(1,463 \mathrm{~cm}^{-1}\right)$ stretching, and $\mathrm{CH}_{2}\left(1,381 \mathrm{~cm}^{-1}\right)$ bending vibrations in the pyrrolidone ring of PVP molecules reveals a charge-transfer-type interaction between the PVP molecules and surface of the Au NP. A significant decay of the emission band intensity (approximately 85\%) in the $\pi \leftarrow \pi^{*}$ band of the PVP molecules at approximately $392 \mathrm{~nm}$ in the presence of Au NPs suggests non-bonding (n) electron transfer from the $\mathrm{O}$ atom of the pyrrolidone ring of PVP molecules to the electron-deficient Au NP. A negative zeta potential of (-) $15.2 \mathrm{mV}$ reveals accumulation of $n$-electrons of the $\mathrm{O}$ atom of the carbonyl group of PVP molecules on the surface of the Au NP. Transmission electron microscopic images of PVP-capped Au NPs corroborate the spectroscopic results.
\end{abstract}

Keywords: Non-hydrocolloid, Surface plasmon resonance, Emission intensity, Charge transfer, Interfacial interaction

\section{Findings Introduction}

Since its discovery, gold $(\mathrm{Au})$ has been fascinating human beings, owing to its luster, high corrosion resistance, outstanding malleability, high thermal and electrical conductivity, and excellent therapeutic properties [1,2]. Gold ash (widely known as swarna bhasma) has been used as medicine in ayurveda, an ancient Indian medical science based on herbs and herbomineral preparation [1,2]. However, until the nineteenth century, little interest was shown by researchers because of the inertness and high cost of gold. In 1857, Michael Faraday published the first report on the synthesis and optical properties of Au nanoparticles (NPs) in a colloid. Since then, noble metal NPs have been

\footnotetext{
* Correspondence: mano.silicon@gmail.com

${ }^{1}$ Chemistry Department, Silicon Institute of Technology, Silicon Hills, Bhubaneswar 751 024, India

${ }^{2}$ Materials Science Centre, Indian Institute of Technology, Kharagpur 721 302,
} India

attracting considerable interest in academia and industries, owing to their potential applications in the field of non-linear optics [3], photoluminescence [3], sensing [3,4], surface-enhanced Raman scattering [5], biomedicine [3-6], catalysis [3-6], photonics [5-7], memory devices [5-7], and heat transfer [8,9] and because of their unique physical, electronic, magnetic, thermal, optical, and biomedical properties. Among the various noble metal NPs, $\mathrm{Au}$ is widely studied by various research groups because it possesses distinctive catalytic activity, superb thermal stability, easy surface modification, low cytotoxicity, and excellent biocompatibility [6,10-12].

Noble metal NPs (NMNPs) exhibits brilliant colors due to the surface plasmon resonance (SPR) absorption, an optical phenomenon arising from the resonant oscillation between the electromagnetic wave and valence electrons $[3,4,6,13]$. Simply by controlling the size, shape, aggregation pattern, and dielectric constant of the medium, SPR bands can be tuned throughout the visible 
region and even to the near-IR region [3,6,13,14]. In this regard, various bottom-up approaches, such as UV irradiation [6,7,15], chemical [3-6], thermochemical [3,6], sonochemical $[3,6]$, and electrochemical reduction [16], have been reported for the synthesis of stable Au NPs of controlled shapes and sizes. Gold NPs of various structural architectures (e.g., rods, plates, disks, cubes, spheres, and stars) can be synthesized by proper manipulation of experimental parameters in the presence of surface-capping agents in the form of surfactants [3,17], polymers [3-7], and dendrimers [3,6]. However, among the various encapsulating agents, a macroscopic ligand especially a hydrophilic polymer like poly(vinylpyrrolidone) (PVP) is widely used in the synthesis of NMNPs $[4-6,18,19]$. It is an amphiphilic polymer well known for its nontoxicity, excellent biodegradability, good complexation ability, and exceptional medicinal properties [4,6,18-20]. Because of its unique structure, presence of a lone pair of electrons on $\mathrm{N}$ and $\mathrm{O}$ atoms of lactam unit, and ability to generate active binding sites upon mesomerism in the presence of hydrogen donors [21], PVP was found to form charge transfer $(\mathrm{CT})$ complexes with fullerene $\left(\mathrm{C}_{60}\right)$ [22,23], iodine [24], and metal NPs [3-6,18,19]. Thus, PVP possesses an exclusive combination of chemical, physicochemical, and biological properties.

Interaction of PVP molecules with metal NPs has been studied by various researchers using UV-Raman spectroscopy, Fourier transform infrared (FTIR) spectroscopy, emission spectroscopy, zeta potential, and X-ray photoemission spectroscopy (XPS) [4-7,18,19,25-37]. Seoudi et al. [15] have observed a shift in the band position of $\mathrm{C}=\mathrm{O}$ and $\mathrm{C}-\mathrm{N}$ stretching frequencies in the vibrational spectrum of PVP in the presence of Au NPs and ascribed such band shifting to a donor-acceptor-type interaction between the carbonyl group of PVP molecules and Au NP. Borodko et al. [25] have observed a marked enhancement in the band intensity of $\mathrm{C}=\mathrm{O}$ and $\mathrm{C}-\mathrm{N}$ stretching vibrations in the pyrrolidone ring of PVP molecules when Pt NPs interact with the surface PVP molecules via a non-bonding $(n)$ electron-rich $\mathrm{C}=\mathrm{O}$ moiety. Grace and Pandian [26] have observed a small blueshift in the $\mathrm{C}=\mathrm{O}$ stretching frequency (about 10 $\mathrm{cm}^{-1}$ ) of the PVP molecule in the presence of Au NPs, owing to a surface interaction between the $\mathrm{C}=\mathrm{O}$ group of the PVP molecule and Au NP. An enhancement in the IR absorption by a factor of approximately 20 was reported for an organic molecule coated by a $5-\mathrm{nm} \mathrm{Ag}$ metal overlayer [27]. As suggested in the said report, the surface-enhanced IR absorption results from an augmentation in the electric field due to collective electron resonances associated with the island nature of the thin metal film. Osawa and Ikeda [28] studied the IR spectra of thin organic films of $p$-nitrobenzoic acid deposited on $\mathrm{Ag}$ island films evaporated on a $\mathrm{CaF}_{2}$ substrate.
Improvement in the IR absorption of organic molecule in the presence of $\mathrm{Ag}$ island films results from the enhancement of electromagnetic field, an increase in vibrational polarizabilities, and orientation of the chemisorbed molecule. Quenching in the emission intensity of fluorophors (e.g., pyrene, organic dye, amino acids) in the presence of $\mathrm{Au}$ NPs was attributed to an interaction between donor and acceptor via charge/energy transfer from the electron donor fluorescent materials to the electron acceptor NP [32-34]. An increased zeta value in the Au-PVP colloid as compared to the mother PVP solution (without NP) was ascribed to the accumulating electrons of the $\mathrm{O}$ atom of the pyrrolidone group on the surface of the Au NP [19,22,35-37]. Negative shift in the binding energies of the doublet Au4 $f$ peak as compared to the bulk $\mathrm{Au}$ was ascribed to surface interaction between the Au NP and the capping agent [5,7,19,30-32].

Herein, we discuss a simple chemical reduction method to synthesize Au NPs from a gold hydroxide, a new precursor salt [19], in the presence of a macroscopic stabilizer and reducer like PVP molecules in an alcoholic medium. 1-Butanol is chosen as reaction medium as this organic solvent is non-anesthetic, nontoxic, biodegradable, and non-mutagenic. It is used as artificial flavorant in butter, cheese, whiskey, ice cream, and in a wide variety of eatables or drinks [38]. Again, an organic solvent found to provide low interfacial energies is needed for a high degree of control during solution and surface processing [17]. Also, $\mathrm{Au}$ NPs synthesized in an organic medium offer excellent control and uniformity of size and possess exceptional processability [39]. The interaction between Au NPs and PVP molecules in 1-butanol has been studied by using UV-visible spectroscopy, FTIR spectroscopy, emission spectroscopy, XPS, zeta potential, and transmission electron microscopy. Though a lot of literatures are available on the study of the interaction between $\mathrm{Au}$ NPs (i.e., usually obtained from hydrated $\mathrm{HAuCl}_{4}$ precursor salt) and PVP molecules in both aqueous and non-aqueous media, no literature is available on the said topic in an alcoholic medium like 1-butanol. Hence, in this article we report a spectroscopy-based study of the interaction between Au NPs (i.e., obtained from gold hydroxide, a new precursor salt) and PVP molecules in 1-butanol.

\section{Materials and methods Materials}

Gold hydroxide $\mathrm{Au}(\mathrm{OH})_{3}$ powder of $99.9 \%$ purity was purchased from Alfa Aesar (Ward Hill, MA, USA), while PVP $(25 \mathrm{kDa})$ and 1-butanol were purchased from SigmaAldrich (St. Louis, MO, USA) and Merck (Whitehouse Station, NJ, USA), respectively. All the chemicals were used as received without any purification. 


\section{Synthesis of Au colloid}

At first, an alcoholic stock solution of PVP $(40 \mathrm{~g} / \mathrm{L})$ was prepared in 1-butanol by mechanical stirring for $3 \mathrm{~h}$ at $60^{\circ} \mathrm{C}$ to $70^{\circ} \mathrm{C}$. Then, we prepared a stock solution of 1.2 $\mathrm{mM}$ gold nitrate $\mathrm{Au}\left(\mathrm{NO}_{3}\right)_{3}$ by dissolving $3 \mathrm{mg}$ of gold hydroxide $\mathrm{Au}(\mathrm{OH})_{3}$ powder in $10 \mathrm{~mL}$ dilute $\mathrm{HNO}_{3}$ by magnetic stirring for $10 \mathrm{~min}$ at room temperature. After this, $0.01 \mathrm{~mL}$ of gold nitrate solution was added to 5 $\mathrm{mL}$ of PVP solution in 1-butanol taken in a $25-\mathrm{mL}$ beaker covered with a watch glass. A purple-colored nonhydrocolloid consisting of approximately $3 \mu \mathrm{M}$ Au NPs with $40 \mathrm{~g} / \mathrm{L}$ PVP molecules was obtained after magnetic stirring for 10 to $20 \mathrm{~min}$ at $50^{\circ} \mathrm{C}$. The obtained stable $\mathrm{Au}$ colloid was studied in terms of the optical spectroscopy and microstructure.

\section{Experimental measurements}

The UV-visible spectra of the PVP solution with and without $\mathrm{Au}$ NPs were recorded under identical conditions on a PerkinElmer double beam spectrophotometer (LAMBDA 1050, PerkinElmer, Waltham, MA, USA). The sample was filled in a transparent cell of quartz (10-mm optical length), and the spectrum was recorded against a reference (1-butanol with $40 \mathrm{~g} / \mathrm{L} \mathrm{PVP}$, or 1-butanol) in an identical cell. Vibrational/FTIR spectra of the solution have been studied with a FTIR spectrometer (model NEXUS-870, Thermo Nicolet Corporation, Madison, WI, USA). The spectra have been recorded in an attenuated total reflectance (ATR) mode using a ZnSe crystal as a sample holder. The emission spectra have been recorded with a computer-controlled PerkinElmer (model-LS 55) luminescence spectrometer in conjugation with a redsensitive PMT detector (RS928) and a high-energy pulsed xenon discharge lamp as an excitation source (average power $7.3 \mathrm{~W}$ at $50 \mathrm{~Hz}$ ). A quartz cell with a $10-\mathrm{mm}$ width hosted the sample. Zeta potential $(\xi)$ and surface conductivity $\left(\sigma_{\mathrm{sc}}\right)$ were measured by using a Malvern Nano ZS instrument (Malvern Instruments, Westborough, MA, USA) using phase analysis light scattering technique. Diluted samples were sonicated for $60 \mathrm{~s}$ prior to measurements. XPS spectrum was collected on a VG ESCALAB MK-II spectrometer (Thermo VG Scientific, East Grinstead, UK) with a monochromatic MgK $\alpha$ source ( $\mathrm{h} v=1,253.6 \mathrm{eV}$ ) operated at $12 \mathrm{kV}$ and $20 \mathrm{~mA}$ at $10^{-8} \mathrm{~Pa}$. The sample was prepared by drop-casting a small aliquot of Au colloid with PVP in 1-butanol on a silica substrate and dried in desiccators by keeping it overnight at room temperature. The microscopic image of Au NPs with PVP molecules was studied with a transmission electron microscope (TEM) using JEM-2100 (JEOL, Tokyo, Japan). TEM samples were prepared by placing one drop of diluted solution on a carbon-coated 400-mesh copper grid and allowing the sample to dry in desiccators at room temperature.

\section{Results and discussion}

\section{UV-visible and XPS spectra}

Figure 1 shows the UV-visible spectra of (a) $40 \mathrm{~g} / \mathrm{L}$ PVP molecules, (b) $3 \mu \mathrm{M}$ Au NPs without PVP, and (c) $3 \mu \mathrm{M}$ $\mathrm{Au}$ NPs with PVP in 1-butanol. As evident from the spectrum (b), Au NPs without any encapsulating agent like PVP show a SPR band at $543 \mathrm{~nm}$. In the presence of PVP, the blueshift in the typical SPR band to $532 \mathrm{~nm}$ (as shown in Figure 1 (c)) is ascribed to the quantum confinement effect $[3,13]$. Such effect arises when Au NPs are covered with a thin film of a dielectric material such as polymeric layer which helps in congregating $n$-electrons of PVP on the Au surface $[13,22,40]$. Again, such a large molar extinction coefficient (here, $\varepsilon=6.9 \times 10^{4} \mathrm{M}^{-1} \mathrm{~cm}^{-1}$ ) is observed when PVP gets adsorbed on the surface of the $\mathrm{NP}$ and helps in altering the electronic properties of $\mathrm{Au}$ NPs by accumulating $n$-electrons of $\mathrm{C}=\mathrm{O}$ moiety of PVP molecules on the Au surface in the Au-PVP nanocomposite $[13,22,40]$. The PVP solution is found to be totally transparent in the visible region (as shown in Figure 1 (a)).

XPS spectrum was recorded to study the surface interaction between NP and PVP molecules. It also helps in knowing the chemical state of Au NPs in the colloid. Figure 2 depicts the XPS spectrum recorded for $4 f$ photoelectrons of the Au NP without PVP and with PVP for comparison of the results. As depicted in Figure 2 (a), XPS spectrum in the Au NP in the absence of a surfaceencapsulating agent shows a Au4 $f$ band at a binding energy of 86.75 and $83.05 \mathrm{eV}$ assigned to Au $4 f_{5 / 2}$ and Au4 $f_{7 / 2}$ peaks, respectively. In Figure 2 (b), the deconvolution of the Au $f f$ doublet band group shows one band at a binding energy of $86.23 \mathrm{eV}$ and other one at $82.56 \mathrm{eV}$ assigned to Au $4 f_{5 / 2}$ and $\mathrm{Au} 4 f_{7 / 2}$ peaks, respectively. Hence, a decrease in binding energy of the Au $f f$ band (i.e., approximately $0.52 \mathrm{eV}$ in $4 f_{5 / 2}$ and approximately $0.49 \mathrm{eV}$ in $4 f_{7 / 2}$ ) in the

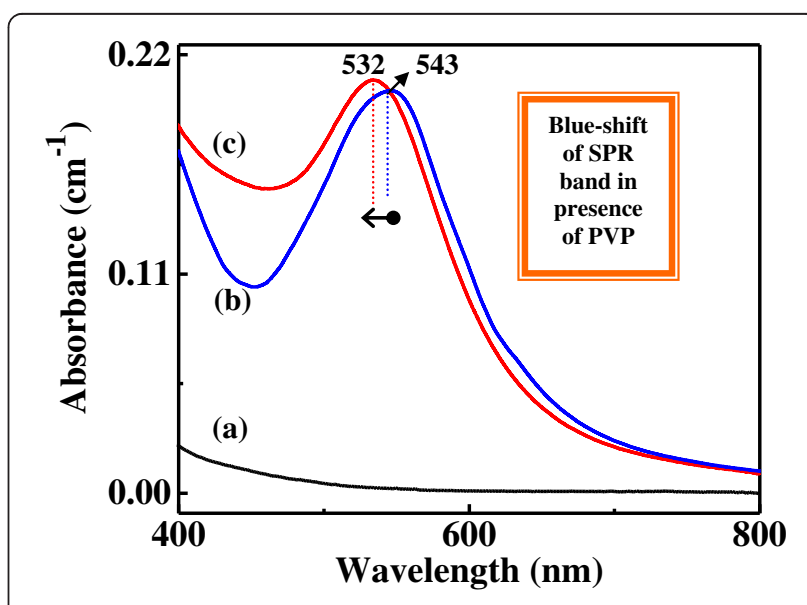

Figure 1 UV-visible absorption spectra. (a) $40 \mathrm{~g} / \mathrm{L}$ PVP, (b) $3 \mu \mathrm{M}$ Au NPs without PVP, and (c) $3 \mu \mathrm{M}$ Au NPs with PVP in 1-butanol. 


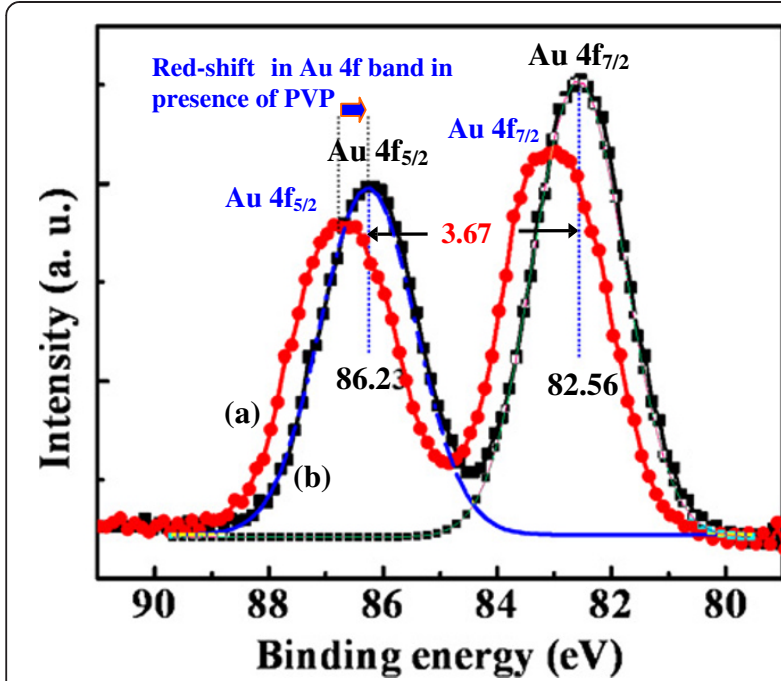

Figure 2 XPS spectra showing the Au4f band. (a) $3 \mu \mathrm{M}$ Au NPs without PVP and (b) $3 \mu \mathrm{M}$ Au NPs with PVP in 1-butanol.

presence of PVP molecules reveals interfacial interaction between the Au NP and PVP molecule [29,31,41,42]. For both samples, a spin-orbit splitting of approximately $3.7 \mathrm{eV}$ confirms reduction of $\mathrm{Au}^{3+}$ to $\mathrm{Au}^{0}$ valance state in the reaction medium [7,29-31]. A similar effect has already been reported in the PVP-capped Au NP and Au-metallized polycarbonate $[18,31]$.

\section{FTIR and emission spectrum}

As FTIR spectroscopy is a powerful tool to investigate the structure, bonding, and reactivity of matter, the interaction between PVP molecules and Au NPs was studied in terms of vibrational spectra. The vibrational bands in PVP molecules (a) before and (b) after adding a specific amount of Au NPs are compared in Figure 3.

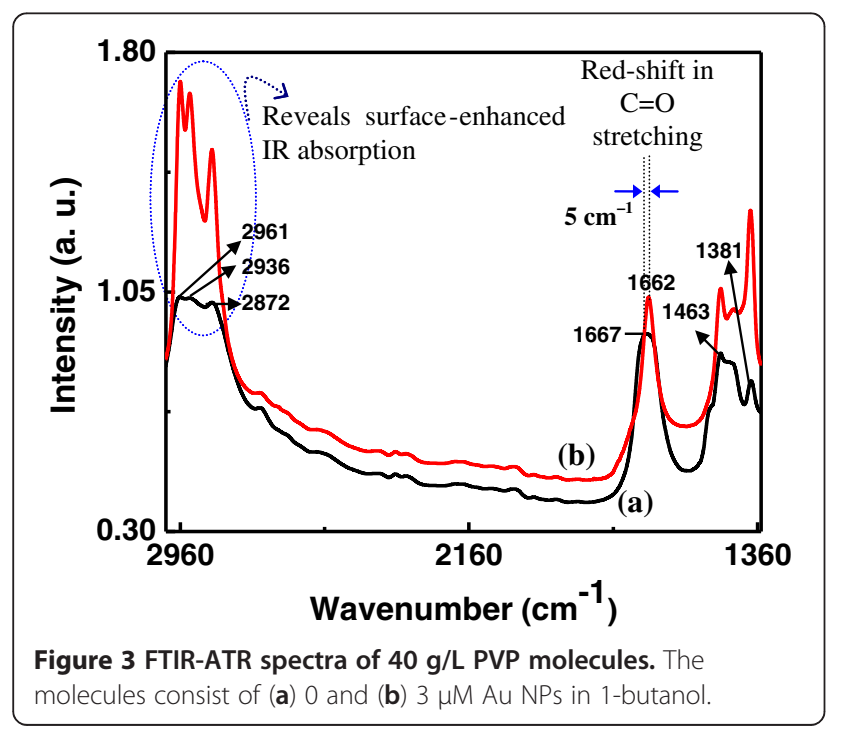

A marked enhancement in band intensity in $\mathrm{C}-\mathrm{H}(2,961$, 2,936, 2,872 $\left.\mathrm{cm}^{-1}\right)$ stretching, C-N $\left(1,463 \mathrm{~cm}^{-1}\right)$ stretching, and $\mathrm{CH}_{2}\left(1,381 \mathrm{~cm}^{-1}\right)$ bending vibrations in the pyrrolidone ring of PVP molecules occurs only when PVP molecules get adsorbed on the surface of $\mathrm{Au} N \mathrm{NP}$ via $n$ electron of the $\mathrm{O}$ atom of the pyrrolidone ring $[4,7,19,25]$. Borodko et al. [25] have reported similarly enhanced intensities in these bands in PVP molecules in the presence of Pt NPs. Such enhancement in the vibrational band intensities is a clear indication of surface-enhanced IR absorption in PVP molecules in the presence NPs $[27,28]$. Further, a small red shift (approximately $5 \mathrm{~cm}^{-1}$ ) in the $\mathrm{C}=\mathrm{O}$ stretching vibration from 1,667 to $1,662 \mathrm{~cm}^{-1}$ in the presence of Au NPs implies a weak adsorption of PVP molecules on the $\mathrm{Au}$ surface via the $\mathrm{O}$ atom of the $\mathrm{C}=\mathrm{O}$ group $[7,19,25]$.

The emission spectra of PVP molecules (a) without and (b) with $3 \mu \mathrm{M}$ Au NPs excited at $290 \mathrm{~nm}$ are depicted in Figure 4. The PVP molecules exhibit an intense emission at $392 \mathrm{~nm}$ due to $\pi \leftarrow \pi^{*}$ transition in the carbonyl group [18]. A red shift in this band to 410 $\mathrm{nm}$ in the presence of $\mathrm{Au}$ NPs signifies that some amount of energy of PVP molecules has possibly been lost by the process of electron transfer from the $\mathrm{C}=\mathrm{O}$ group to the electron-deficient Au NP. Again, quenching in the emission intensity (i.e., as much as $85 \%$ ) of PVP molecules in the presence of $3 \mu \mathrm{M}$ Au NPs with $40 \mathrm{~g} / \mathrm{L}$ PVP in 1-butanol suggests the existence of a donoracceptor-type interaction between the PVP molecules and Au NP [32-34].

\section{Zeta potential}

Interaction between the PVP molecules and Au NP was studied by measuring the zeta potential $(\xi)$ of PVP

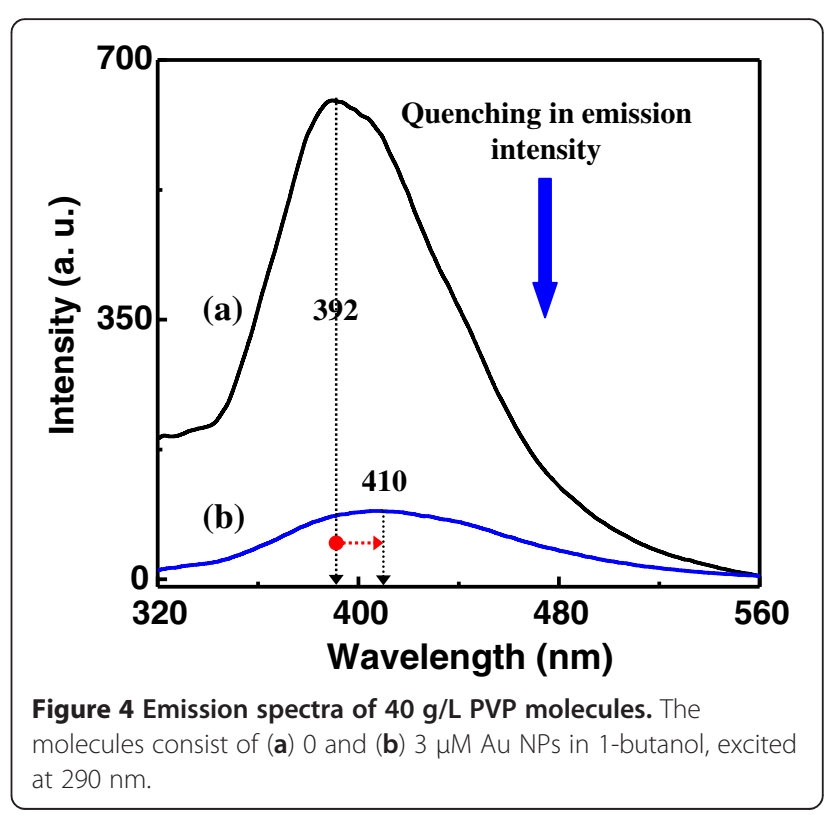




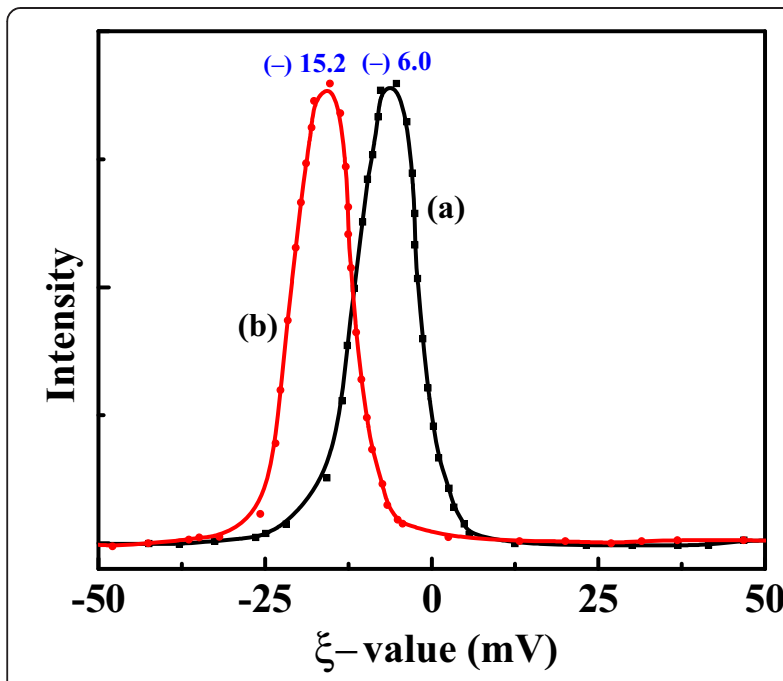

Figure 5 $\xi$-band profile of $\mathbf{4 0} \mathrm{g} / \mathrm{L}$ PVP molecules. The molecules consists of (a) 0 and (b) $3 \mu \mathrm{M}$ Au NPs in 1-butanol at $\mathrm{pH}=7.5$ and 7.4, respectively.

molecules with and without Au NPs. As shown in Figure 5, sample (a) of $40 \mathrm{~g} / \mathrm{L}$ PVP molecules displays a $\xi$-band at $(-) 6.0 \mathrm{mV}$ with surface conductivity $\left(\sigma_{\mathrm{sc}}\right)=$ $0.014 \mathrm{mS} / \mathrm{cm}$ at $\mathrm{pH} 7.5$, whereas an Au colloid (b) consisting of $3 \mu \mathrm{M}$ Au NPs with $40 \mathrm{~g} / \mathrm{L}$ PVP results in a larger $\xi$-value of $(-) 15.2 \mathrm{mV}$, with an enhanced $\sigma_{\mathrm{sc}}=$ $0.125 \mathrm{mS} / \mathrm{cm}$ at $\mathrm{pH}$ 7.4. A larger $\xi$-value with an enhanced $\sigma_{\mathrm{sc}}$ value in Au colloid suggested a larger localized surface charge density that resulted from accumulation of $n$-electrons of the $\mathrm{C}=\mathrm{O}$ group of $\mathrm{PVP}$ molecules on the surface of the Au NP [19,22,35-37].
An analogous effect has already been reported in PVPcapped fullerene $\left(\mathrm{C}_{60}\right)$ nanofluids in 1-butanol where PVP acts as electron donor [22].

\section{Microstructural investigations}

The morphology of PVP-encapsulated Au NPs can be studied with TEM. Figure 6 depicts microscopic images obtained from Au colloid with PVP molecules. The Au NPs are encaged in PVP molecules in such a way that they appear mostly as faceted particles with diameters of 5 to $20 \mathrm{~nm}$. Moreover, the image which displays a marked polydispersity in distributions of size may be ascribed to the low content (i.e., $40 \mathrm{~g} / \mathrm{L}$ ) of the size- and shape-regulating agent (i.e., here PVP) in the colloidal solution [4-6]. As can be seen from the image, a typical hexagonal plate of PVP-encapsulated Au NP (marked as ' $\mathrm{P}$ ' in the image) demonstrates a distinct surface layer of PVP (as a whitish contrast of 2.9-nm thickness) which adheres firmly to the darkish region of the $\mathrm{Au}$ NP. Rahme et al. [43] have reported core-shell structures in triblock copolymer-capped Au NPs. Such type of feature has already been reported in PVP-encapsulated NPs $[18,19]$. A high-resolution TEM image (Figure $6 \mathrm{~b}$ ) of the PVP-encapsulated Au NP displays lattice fringes and confirms the crystalline structure of the Au NP with an interplanar spacing $0.237 \mathrm{~nm}$ corresponding to the (111) plane [18]. The polycrystalline nature of Au NP was confirmed by diffraction rings (Figure 6c) obtained from the bulk of the Au NP. Those electron diffraction rings could be assigned to the (111), (200), (220), (311), and (222) planes of face-centered cubic Au $[5,18]$.

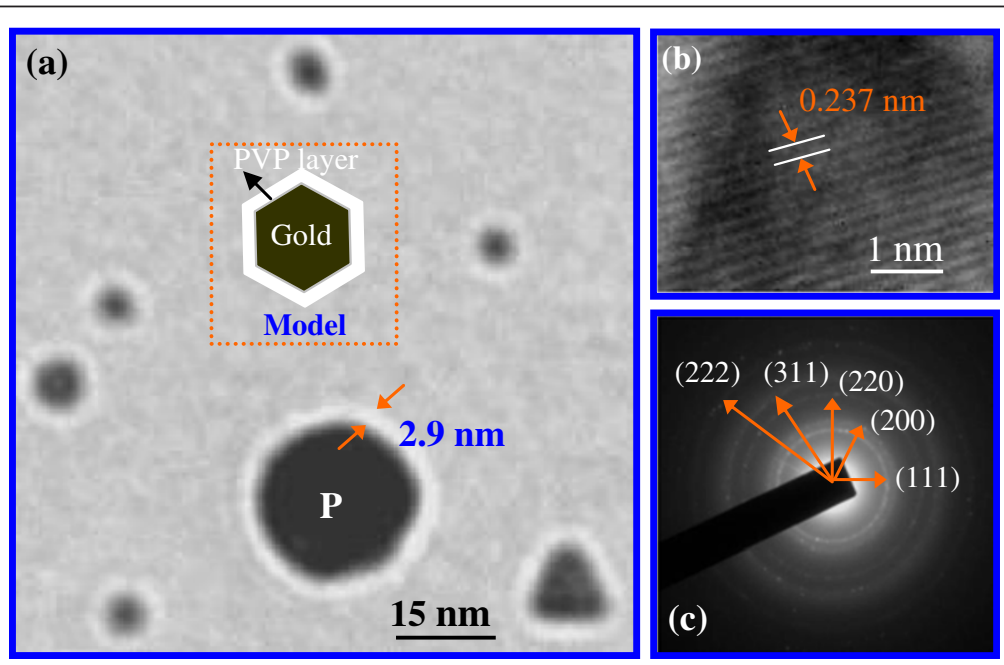

Figure 6 Typical TEM images taken from $3 \mu \mathrm{M}$ Au NPs with 40 g/L PVP molecules in 1-butanol. (a) Typical hexagonal plate of PVPencapsulated Au NP. (b) Lattice fringes reveal crystalline nature of PVP-encapsulated Au NPs. (c) Rings of an electron diffraction pattern of NP corresponds to (111), (200), (220), (311), and (222) planes of the face-centered cubic Au atom. A model drawn in support of the TEM images demonstrating the PVP-coated Au hybrid nanostructure is affixed as an inset in (a). 


\section{Conclusions}

A donor-acceptor-type of interaction exists between the electron-deficient $\mathrm{Au} \mathrm{NP}$ and electron donors of the PVP molecules in a non-aqueous colloid as substantiated by UV-visible spectroscopy, FTIR spectroscopy, XPS, emission spectroscopy, zeta potential, and TEM. Formation of Au NPs in the colloid was confirmed by UVvisible and XPS spectra. A significant quenching in the emission intensity of the $\pi \leftarrow \pi^{*}$ band of the PVP molecules and marked enhancement in the vibrational band intensities in $\mathrm{C}-\mathrm{H}$ stretching, $\mathrm{C}-\mathrm{N}$ stretching, and $\mathrm{CH}_{2}-$ bending vibrations in the pyrrolidone ring of PVP molecules signify chemisorption of PVP molecules on the surface of the Au NP. A larger $\xi$-value as found in the PVP-capped Au NP compared to that in pure PVP suggests more charge confinement as a result of charge transfer from PVP molecules to the surface of the $\mathrm{Au}$ NP. Spectral findings are well reflected in TEM images. Probing the interaction between the PVP molecules and $\mathrm{Au} \mathrm{NP}$ is imperative because of possible medicinal, biosensing, bioconjugation, and catalytic applications.

\section{Competing interests}

The authors declare that they have no competing interests.

\section{Authors' contributions}

MB conceived the study, carried out all the experiments, and drafted the manuscript. SR helped in writing the analysis part and corrected the manuscript. Both authors read and approved the final manuscript.

\section{Acknowledgments}

This work has been supported by the Silicon Institute of Technology, Silicon Hills, Bhubaneswar, India.

Received: 22 August 2012 Accepted: 2 March 2013

Published: 28 March 2013

\section{References}

1. Edwards, PP, Thomas, JM: Gold in a metallic divided state-from Faraday to present-day nanoscience. Angew. Chem. Int. Ed. 46, 5480-5486 (2007)

2. Hutchings, GJ, Brust, $M$, Schmidbaur, H: Gold-an introductory perspective. Chem. Soc. Rev. 37, 1759-1765 (2008)

3. Daniel, MC, Astruc, D: Gold nanoparticles: assembly, supramolecular chemistry, quantum-sized-related properties, and applications toward biology, catalysis, and nanotechnology. Chem. Rev. 104, 293-346 (2004)

4. Hoppe, CE, Lazzari, M, Pardiñas-Blanco, I, López-Quintela, A: One-step synthesis of gold and silver hydrosols using poly(N-vinyl-2-pyrrolidone) as a reducing agent. Langmuir 22, 7027-7034 (2006)

5. Kemal, L, Jiang, XC, Wong, K, Yu, AB: Experiment and theoretical study of poly(vinyl pyrrolidone)-controlled gold nanoparticles. J. Phys. Chem. C 112, 15656-15664 (2008)

6. Alexandridis, P: Gold nanoparticle synthesis, morphology control, and stabilization facilitated by functional polymers. Chem. Engg. Technol. 34, 15-28 (2011)

7. Abyaneh, MK, Parmanik, D, Varma, S, Gosavi, SW, Kulkarni, SK: Formation of gold nanoparticles in polymethylmethacrylate by UV irradiation. J. Phys. D: Appl. Phys. 40, 3771-3779 (2007)

8. Shalklvicht, N, Escher, W, Burgi, T, Michel, B, Si-Ahmed, L, Poulikakos, D: On the thermal conductivity of gold nanoparticle colloids. Langmuir 26, 663-670 (2010)

9. Zhang, H, Wu, Q, Lin, J, Chen, J, Xu, Z: Thermal conductivity of polyethylene glycol nanofluids containing carbon coated metal nanoparticles. J. Appl. Phys. 108, 124304-124309 (2010)
10. Chandran, PC, Naseer, M, Udupa, N, Sandhyarani, N: Size controlled synthesis of biocompatible gold nanoparticles and their activity in the oxidation of NADH. Nanotechnology 23, 015602 (2012)

11. Thanh, NTK, Green, L: Functionalization of nanoparticles for biomedical applications. Nano Today 5, 213-230 (2010)

12. Jin, R: Quantum-sized thiolate protected gold nanoclusters. Nanoscale 2 , 343-362 (2010)

13. Kelly, KL, Coronado, E, Zhao, LL, Schatz, GC: The optical properties of metal nanoparticles: the influence of size, shape, and dielectric environment. J. Phys. Chem. B 107, 668-677 (2003)

14. Balamurugan, B, Maruyama, T: Evidence of an enhanced interband absorption in Au nanoparticles: size-depended electronic structure and optical properties. Appl. Phys. Lett. 87, 143105-143107 (2005)

15. Seoudi, R, Fouda, AA, Elmenshawy, DA: Synthesis, characterization and vibrational spectroscopic studies of different particle size of gold nanoparticle capped polyvinylpyrrolidone. Physica B 405, 906-911 (2010)

16. Nagaraju, DH, Lakshinarayan, V: Electrochemical synthesis of thiol-monolayer -protected clusters of gold. Langmuir 24, 13855-13857 (2008)

17. Balasubramaniam, R, Kim, B, Tripp, SL, Wang, X, Liberman, M, Wei, A: Dispersion and stability studies of resorcinarene-encapsulated gold nanoparticles. Langmuir 18, 3676-3681 (2002)

18. Ram, S: Fecht, $\mathrm{H}-J$ : Modulating up-energy transfer and violet-blue light emission in gold nanoparticles with surface adsorption of poly(vinyl pyrrolidone) molecules. J. Phys. Chem. C 115, 7817-7828 (2011)

19. Behera, M, Ram, S: Synthesis and characterization of core-shell gold nanoparticles with poly(vinyl pyrrolidone) from a new precursor salt. Appl. Nanosci (2012). doi:10-1007/s13204-012-0076-x

20. Kamada, H, Tsutsumi, Y, Kamada, KS, Yamamoto, Y, Yoshioka, Y, Okamoto, T, Nakagawa, S, Nagata, S, Mayumi, T: Synthesis of a poly(vinylpyrrolidone-codimethyl maleic anhydride) co-polymer and its application for renal drug targeting. Nat. Biotechnol. 21, 399-404 (2003)

21. Rothschild, WG: Binding of hydrogen donors by peptide groups of lactams. Identity of the reaction sites. J. Am. Chem. Soc. 94, 8676-8683 (1972)

22. Behera, $M$, Ram, S: Solubilization and stabilization of fullerene $C_{60}$ in presence of poly(vinyl pyrrolidone) molecules in water. J. Incl. Phenom. Macrocycl. Chem. 72, 233-239 (2012)

23. Khairullin, II, Chen, Y, Hwang, L: Evidence for electron charge transfer in the polyvinylpyrrolidone- $C_{60}$ system as seen from ESR spectra. Chem. Phys. Lett. 275, 1-6 (1997)

24. De Faria, DLA, Gil, HAC: De queiróz, AAA: The interaction between polyvinylpyrrolidone and $\mathrm{I}_{2} \mathrm{~s}$ probed by Raman spectroscopy. J. Mol. Str. 479, 93-98 (1999)

25. Borodko, Y, Habas, SE, Koebel, M, Yang, P, Frei, H, Somorjai, GA: Probing the interaction of poly(vinyl pyrrolidone) with platinum nanocrystals by UVRaman and FTIR. J. Phys. Chem. B 110, 23052-23059 (2006)

26. Grace, AN, Pandian, K: One pot synthesis of polymer protected gold nanoparticles and nanoprisms in glycerol. Colloids Surf A290, 138-142 (2006)

27. Hartstein, A, Kirtley, JR, Tsang, JC: Enhancement of the infrared absorption from molecular monolayers with thin metal overlayers. Phys. Rev. Lett. 45, 201-204 (1980)

28. Osawa, M, Ikeda, M: Surface-enhanced infrared absorption of p-nitrobenzoic acid deposited on silver islands films: contribution of electromagnetic and chemical mechanism. J. Phys. Chem. 95, 9914-9919 (1991)

29. Joseph, Y, Besnard, I, Rosenberger, M, Guse, B, Nothofer, HG, Wessels, JM, Wild, U, Knop-Gericke, A, Su, D, Schlögl, R, Yasuda, A, Vossmeyer, T: Selfassembled gold nanoparticle/alkanedithiol films: preparation, electron microscopy, XPS-analysis, charge transfer, and vapour-sensing properties. J. Phys. Chem. B 107, 7406-7413 (2003)

30. Tunc, I, Demirok, UK, Suzer, S: Charging/discharging of Au (core)/Silica (shell) nanoparticles as revealed by XPS. J. Phys. Chem. B 109, 24182-24184 (2003)

31. Patnaik, A, Li, C: Evidence for metal interaction in gold metallized polycarbonate films: an X-ray photoelectron spectroscopy investigation. J. Appl. Phys. 83, 3049 (1998)

32. Dulkeith, E, Morteani, AC, Niedereichholz, T, Klar, TA, Feldmann, J, Levi, SA, Van Vegel, FCJM, Reinhoudt, DN, Möller, M, Gittins, DI: Fluorescence quenching of dye molecules near gold nanoparticles: radiative and nonradiative effect. Phys. Rev. Lett. 89, 203002 (2002)

33. Ghosh, SK, Pal, A, Kundu, S, Nath, S, Pal, T: Fluorescence quenching of 1methylaminopyrene near gold nanoparticles: size regime dependence of the small metallic particles. Chem. Phys. Lett. 395, 366-372 (2004) 
34. Karthikeyan, B: Fluorescence quenching of rhodamine- $6 \mathrm{G}$ in Au nanocomposite polymers. J. Appl. Phys. 108, 0844311 (2010)

35. Van der Zande, BMI, Jan, KGD, Marcel, RB, Albert, PP: Colloidal dispersion of gold rods characterized by dynamic light scattering and electrophoresis. Langmuir 16, 459-464 (2000)

36. Manson, J, Kumar, D, Meenan, BJ, Dixon, D: Polyethylene glycol functionalized gold nanoparticles: the influence of capping density on stability in various media. Gold Bull. 44, 99-105 (2011)

37. Sakai, T, Alexandridis, P: Size-and shape-controlled synthesis of colloidal gold through autoreduction of the auric cation by poly(ethylene-oxide)poly(propylene oxide) block copolymers in aqueous solutions at ambient conditions. Nanotechnology 16, S334 (2005)

38. Butanols: International programme on chemical safety, Environmental health criteria 65. WHO, Geneva (1987). http://www.inchem.org/documents/ ehc/ehc/ehc65.htm. Accessed on 15 August 2012. ISBN 92-4-154265-9

39. Sugunan, A, Thanachayanont, C, Dutta, J, Hilborn, JG: Heavy-metal ion sensors using chitosan-capped gold nanoparticles. Sci. Tech. Adv. Mater. 6, 335-340 (2005)

40. Kim, GM, Wutzler, A, Radusch, HJ, Michler, GH, Simon, P, Sperling, RA, Parak, WJ: One dimensional arrangement of gold nanoparticles by electrospinning. Chem. Mater. 17, 4949-4957 (2005)

41. Tripathy, P, Mishra, A, Ram, S, Fecht, H-J, Bansmann, J, Behm, RJ: X-ray photoelectron spectrum in surface interfacing of gold nanoparticles with polymer molecules in a hybrid nanocomposite structure. Nanotechnology 20, 075701 (2009)

42. Wang, A-Q, Liu, J-H, Lin, T-S, Mou, C-Y: A novel efficient Au-Ag alloy catalyst system: preparation, activity, and characterization. J. Catal. 233, 186-197 (2005)

43. Rahme, K, Oberdisse, J, Schweins, R, Gaillard, C, Marty, JD, Mingotaud, C, Gauffre, F: Pluronics-stabilized gold nanoparticles: investigation of the structure and the polymer-particle hybrid. Chemphyschem 9, 2230-2236 (2008)

doi:10.1186/2228-5326-3-17

Cite this article as: Behera and Ram: Spectroscopy-based study on the interaction between gold nanoparticle and poly(vinylpyrrolidone) molecules in a non-hydrocolloid. International Nano Letters 2013 3:17.

\section{Submit your manuscript to a SpringerOpen ${ }^{\circ}$ journal and benefit from:}

- Convenient online submission

- Rigorous peer review

- Immediate publication on acceptance

- Open access: articles freely available online

- High visibility within the field

- Retaining the copyright to your article

Submit your next manuscript at $\gg$ springeropen.com 